\title{
CRESCIMENTO INICIAL, NÍVEIS CRÍTICOS DE FÓSFORO E FRAÇÕES FOSFATADAS EM ESPÉCIES FLORESTAIS ${ }^{1}$
}

\author{
LUIZ ARNALDO FERNANDES ${ }^{2}$, ANTONIO EDUARDO FURTINI NETO 3 , \\ FERNANDO CAVICCHIOLIFONSECA ${ }^{4}$ E FABIANO RIBEIRO DO VALE 3
}

\begin{abstract}
RESUMO - Foi conduzido um experimento em casa de vegetação, com o objetivo de avaliar o crescimento de plântulas, os níveis críticos de $\mathrm{P}$ e algumas frações fosfatadas, em três espécies florestais submetidas a quatro doses de P. Mudas de aroeirinha (Schinus terenbinthifolius Raddi), paineira (Chorisia speciosa St. Hill.) e jambolão (Syzygium jambolanum Lam.) foram cultivadas em um Latossolo Variação Una, onde foram aplicados $0,150,300$ e $600 \mathrm{mg} \mathrm{dm}^{-3} \mathrm{de}$ P. Aos 180 dias após a germinação, as plantas foram colhidas e submetidas às análises químicas. Sob todas as doses de $\mathrm{P}$, a paineira produziu maior biomassa da parte aérea e das raízes em comparação à aroeirinha e jambolão, além de apresentar maiores teores de $\mathrm{P}$ orgânico ( $\mathrm{Po}$ ) e maior participação relativa do $\mathrm{P}$ orgânico $(\mathrm{Po})$ em relação ao $\mathrm{P}$ total solúvel em ácido em todos os níveis de fertilização fosfatada. O melhor crescimento da paineira foi atribuído a uma maior eficiência nos ajustes metabólicos desta espécie em relação à nutrição fosfatada, o que indica que esta espécie pode ser plantada em solos com diferentes níveis de $\mathrm{P}$
\end{abstract}

Termos para indexação: Schinus terenbinthifolius, Chorisia speciosa, Syzygium jambolanum, plântulas, adubação fosfatada, relação planta-solo

\section{INITIAL GROWING, PHOSPHORUS CRITICAL LEVELS AND PHOSPHATE FRACTIONS IN FOREST SPECIES}

\begin{abstract}
An experiment under greenhouse conditions was carried out at Universidade Federal de Lavras, Minas Gerais State, Brazil, to evaluate the growth of seedlings, phosphorus critical levels and phosphate fractions, in forest species growing under four phosphorus levels. Seedlings of Schinus terenbinthifolius Raddi (aroeirinha), Chorisia speciosa St. Hill. (paineira) and Syzygium jambolanum Lam. (jambolão) were cultivated on an Oxisol fertilized with $0,150,300$ and $600 \mathrm{mg} \mathrm{dm}^{-3}$ of P. The seedlings were harvested 180 days after germination and analysed for $\mathrm{P}$ forms. In all levels of phosphorus addition, the paineira produced higher aerial and root biomass than aroeirinha and jambolão, and presented higher contents of organic phosphorus and higher relative participation of organic phosphorus in the total acid soluble phosphorus under all phosphorus levels. The improved growth rate of paineira was attributed to a greater efficiency in the metabolic adjustments of this species in relation to phosphorus nutrition, indicating that this species can grow in soils of variable $\mathrm{P}$ levels.
\end{abstract}

Index terms: Schinus terenbinthifolius, Chorisia speciosa, Syzygium jambolanum, seedlings, phosphate fertilizers, plant soil relations.

\footnotetext{
${ }^{1}$ Aceito para publicação em 21 de dezembro de 1999. Parcialmente financiado pela CEMIG e FAPEMIG.

${ }^{2}$ Eng. Agrôn., D.Sc., Prof. Adjunto, Núcleo de Ciências Agrárias, Universidade Federal de Minas Gerais (UFMG), Caixa Postal 135, CEP 39404-006 Montes Claros, MG. E-mail: lafernand@ig.com.br

${ }^{3}$ Eng. Agrôn., Dr., Dep. de Ciência do Solo, Universidade Federal de Lavras (UFLA), Caixa Postal 37, CEP 37200-000 Lavras, MG. Bolsista do CNPq. E-mail: afurtini@ufla.br

${ }^{4}$ Eng. Agrôn., Dep. de Ciência do Solo, UFLA.
}

\section{INTRODUÇ̃̃O}

As áreas de nascentes de água e as matas ciliares têm sofrido um processo contínuo de devastação, com grandes conseqüências ecológicas e ambientais. Por esta razão, a sociedade tem-se mobilizado no sentido de preservar as áreas remanescentes e replantar com espécies nativas os locais degradados pela mineração, construção civil, construção de reservatórios das usinas hidrelétricas ou mesmo pela utilização do solo para fins agrícolas. 
Em áreas degradadas, a reconstituição da vegetação pode se dar pelo crescimento das árvores remanescentes ou através do plantio de novas mudas (Larson, 1992). No Brasil, de modo geral, a recomposição dessas áreas tem sido efetuada através de novos plantios, o que exige o conhecimento do comportamento nutricional das espécies usadas com esta finalidade. Geralmente, os solos a serem reflorestados possuem diferentes características químicas, que, associadas ao grande número de espécies florestais nativas com comportamentos nutricionais distintos (Siqueira et al., 1995), indicam que a obtenção de informações sobre as demandas nutricionais, e a resposta dessas espécies à fertilização é de fundamental importância.

A baixa disponibilidade de $\mathrm{P}$ nos solos tropicais é uma das causas que mais limita o crescimento e a produção florestal (Franco, 1984), tornando necessário o fornecimento deste nutriente às árvores via fertilização. Respostas à adubação fosfatada em programas de recuperação de áreas degradadas são relatadas na literatura a respeito de várias espécies (Dias et al., 1991; Sun et al., 1992; Renó, 1994). A resposta de espécies distintas à fertilização fosfatada tem sido explicada pela dinâmica das frações de P na planta. O acompanhamento dos teores de $\mathrm{P}$ inorgânico $(\mathrm{Pi})$ e de $\mathrm{P}$ orgânico $(\mathrm{Po})$ tem auxiliado no entendimento do comportamento em crescimento e na eficiência de utilização do nutriente pelas plantas (Fabres et al., 1987; Furtini Neto, 1994).

O objetivo deste trabalho foi avaliar o crescimento de plântulas, os níveis críticos de $\mathrm{P}$ e a distribuição de algumas frações fosfatadas em três espécies florestais submetidas à fertilização com $\mathrm{P}$, na fase de mudas.

\section{MATERIAL E MÉTODOS}

O experimento foi conduzido em casa de vegetação no Departamento de Ciência do Solo da Universidade Federal de Lavras (UFLA), no período de março a setembro de 1996, utilizando-se como substrato um Latossolo Variação Una $(\mathrm{LU})$, naturalmente ácido ( $\mathrm{pH}$ água $=4,6 \mathrm{e}$ $\mathrm{Al}=1,3 \mathrm{cmol}_{\mathrm{c}} \mathrm{dm}^{-3}$ ), proveniente do município de Itutinga, MG. O solo foi coletado na camada de 0 a $20 \mathrm{~cm}$, e após secagem ao ar e peneiramento $(4 \mathrm{~mm})$ foi acondicionado em vasos de $3 \mathrm{dm}^{3}$. Cada vaso constituiu uma unidade experimental.
Efetuou-se a aplicação de $\mathrm{CaCO}_{3}$ e $\mathrm{MgCO}_{3}$ p.a., na relação $\mathrm{Ca}: \mathrm{Mg}$ de 4:1, para elevar a saturação por bases a $70 \%$, além de uma adubação básica de plantio com $30 \mathrm{mg}$ de $\mathrm{N} ; 100 \mathrm{mg}$ de $\mathrm{K} ; 50 \mathrm{mg}$ de $\mathrm{S} ; 0,5 \mathrm{mg}$ de $\mathrm{B} ; 1,5 \mathrm{mg}$ de Cu ; 5,0 mg de Zn; 0,1 mg de Mo; 3,6 mg de Mn e 1,5 mg de Fe por $\mathrm{dm}^{3}$ de solo. Os tratamentos consistiram na aplicação de $0,150,300$ e $600 \mathrm{mg} \mathrm{dm}^{-3}$ de $\mathrm{P}$, na forma de sais p.a. $\left(\mathrm{KH}_{2} \mathrm{PO}_{4} ; \mathrm{NH}_{4} \mathrm{H}_{2} \mathrm{PO}_{4}\right.$ e $\left.\mathrm{Ca}\left(\mathrm{H}_{2} \mathrm{PO}_{4}\right)_{2}\right)$. O delineamento experimental utilizado foi o inteiramente casualizado, arranjado num esquema fatorial $4 \times 3$ (quatro doses de $\mathrm{P}$ e três espécies florestais), com quatro repetições.

As espécies estudadas foram: aroeirinha (Schinus terenbinthifolius Raddi), paineira (Chorisia speciosa St. Hill.), e jambolão (Sygygium jambolanum Lam.), classificadas como 'pioneira', 'clímax exigente em luz' e 'clímax tolerante à sombra', respectivamente (Davide et al., 1995).

Após a incubação com calcário e aplicação dos tratamentos, foram analisados alguns parâmetros físicos e químicos do solo (Tabela 1); em seguida, efetuou-se a semeadura diretamente nos vasos, distribuindo-se dez sementes por vaso. Duas semanas após a germinação, realizou-se o desbaste, deixando-se duas plântulas por vaso. Durante o período experimental (210 dias), foram realizadas seis aplicações de $\mathrm{N}$ na forma de $\mathrm{NH}_{4} \mathrm{NO}_{3}$, num total de $150 \mathrm{mg} \mathrm{dm}^{-3}$ de N. A umidade do solo foi mantida em torno de $60 \%$ do volume total de poros, sendo monitorada através de pesagens diárias.

Aos 180 dias após a emergência, foram avaliados o diâmetro do caule na altura do colo e altura das plantas. Em seguida, foram colhidas duas folhas fisiologicamente maduras a partir do ápice de cada planta, para o fracionamento do P. Essas amostras foram colocadas em ácido perclórico $0,2 \mathrm{~N}$, e congeladas, para, posteriormente, ser analisadas em relação a $\mathrm{P}$ total solúvel em ácido (Pts), $\mathrm{P}$ inorgânico solúvel em ácido $(\mathrm{Pi})$, e, por diferença, $\mathrm{P}$ orgânico solúvel em ácido (Po), conforme método de Smillie \& Krotkov (1960) e Hogue et al. (1970), modificado por Martinez (1992). O restante do material vegetal foi separado em parte aérea e sistema radicular, secado em estufa a $70^{\circ} \mathrm{C}$, pesado para as determinações de matéria seca da parte aérea e raiz, e moído para a determinação do $\mathrm{P}$ total $(\mathrm{Pt})$ nos tecidos vegetais por digestão nitroperclórica.

Os dados obtidos foram submetidos a análise de variância, sendo as espécies estudadas comparadas pelo teste de Tukey. Modelos de regressão foram ajustados para as variáveis de crescimento como dependentes das doses de $\mathrm{P}$. Quanto à produção de matéria seca da parte aérea, nas espécies em que as equações de resposta foram quadráticas, estimaram-se as doses críticas de $\mathrm{P}$ equivalentes à obtenção de $90 \%$ da produção máxima (Fabres et al., 1987). Quanto às espécies em que as equações obtidas 
foram lineares, adotou-se o critério de $100 \%$ da maior produção para estimar as doses de $\mathrm{P}$ correspondentes a essas produções (doses críticas). Foram também ajustadas equações de regressão para as frações de $\mathrm{P}$ na planta como variáveis dependentes das doses de $\mathrm{P}$, em cada espécie florestal. Pela substituição das doses críticas de P nessas equações, obtiveram-se os níveis críticos das diferentes frações de P na parte aérea de cada espécie.

A efíciência de utilização do P na parte aérea foi calculada pelo índice proposto por Siddiqi \& Glass (1981), definido pela expressão $\mathrm{EU}=\mathrm{W} / \mathrm{C}$, em que EU: eficiência de utilização; W: matéria seca total; C: concentração do nutriente no tecido.

\section{RESULTADOS E DISCUSSÃO}

\section{Crescimento das plântulas}

As espécies florestais apresentaram crescimento distinto, em função das doses de $\mathrm{P}$ aplicadas (Fig. 1). A paineira foi a espécie que apresentou a maior produção de matéria seca da parte aérea (MSPA), raiz (MSRA) e total (MSTOT), em todas as doses de P, exceto na dose de $600 \mathrm{mg} \mathrm{dm}^{-3}$, enquanto aroeirinha e jambolão não diferiram entre si quanto à produção de biomassa em todos os níveis de fertilização fosfatada.

Quanto ao crescimento em altura, apenas nas doses de 0 e $150 \mathrm{mg} \mathrm{dm}^{-3}$ ocorreram diferenças entre as espécies (Fig. 1). Na ausência de P, a paineira apresentou o maior crescimento em altura, e na dose de $150 \mathrm{mg} \mathrm{dm}^{-3}$, o jambolão apresentou menor crescimento do que as duas outras espécies (Fig. 1). A paineira também apresentou o maior diâmetro do caule em todas as doses do nutriente, enquanto a aroeirinha e o jambolão tiveram comportamentos semelhantes entre si. Um resultado a ser destacado foi a grande produção de biomassa radicular pelas plantas de paineira, em todas as doses de P (Fig. 1). Sob limitado suprimento de $\mathrm{P}$, as raízes das plantas de todas as espécies, principalmente a paineira, mostraram-se drenos preferenciais de fotossintatos, se comparadas com a parte aérea. O crescimento radicular é favorecido em solos deficientes em nutrientes, notadamente em N e em P (Marschner et al., 1996), como estratégia para extrair o máximo do nutriente presente no solo (Clarkson, 1985). Neste caso, a paineira seria mais eficiente do que as demais espécies no ajuste do crescimento das raízes.

De modo geral, ao se aumentar o fornecimento de $\mathrm{P}$, ocorreu sensível aumento na produção de MSPA em relação à MSRA em todas as espécies (Fig. 1). Uma vez que o $\mathrm{P}$ é um dos nutrientes que mais afeta o crescimento das raízes (Clarkson,1985), este comportamento era esperado, e as variações observadas devem estar associadas às diferenças de resposta das espécies ao P. Além do efeito direto da maior MSRA no crescimento da paineira, pela exploração de um maior volume de solo, deve-se ressaltar também a influência da geometria das raízes no crescimento e na aquisição de P (Föhse et al., 1991), onde espécies com sistema radicular mais fino e fasciculado teriam maior facilidade de aquisição do nutriente, principalmente sob condições de limitada disponibilidade no solo. Embora não tenha sido objeto deste trabalho estudar a morfologia do sistema radicular, a paineira, visualmente, apresentou um sistema radicular mais fino e ramificado em relação às outras espécies estudadas.

Em todas as espécies, a produção de MSTOT, em função das doses de P, foi ajustada por uma função quadrática, atingindo a máxima produção, ao passo

TABELA 1. Características químicas e físicas do Latossolo Variação Una após a aplicação da adubação de plantio e das doses de $\mathbf{P}$.

\begin{tabular}{|c|c|c|c|c|c|c|c|c|c|c|}
\hline Dose de P & $\mathrm{pH}$ & $\mathrm{P}$ & $\mathrm{K}$ & $\mathrm{Ca}$ & $\mathrm{Mg}$ & $\mathrm{H}+\mathrm{Al}$ & M.O & Areia & Silte & Argila \\
\hline$\left(\mathrm{mg} \mathrm{dm}^{-3}\right)$ & & \multicolumn{2}{|c|}{$---\left(\mathrm{mg} \mathrm{dm}^{-3}\right)----$} & \multicolumn{3}{|c|}{$-----\left(\mathrm{cmol}_{\mathrm{c}} \mathrm{dm}^{-3}\right)$------ } & \multicolumn{4}{|c|}{ - $\left(\mathrm{g} \mathrm{kg}^{-1}\right)$} \\
\hline 0 & 5,3 & 1 & 100 & 1,1 & 0,3 & 2,3 & 16 & 620 & 150 & 230 \\
\hline 150 & 5,9 & 5 & 97 & 1,3 & 0,3 & 2,3 & 16 & 620 & 150 & 230 \\
\hline 300 & 6,2 & 17 & 100 & 0,8 & 0,3 & 2,6 & 16 & 620 & 150 & 230 \\
\hline 600 & 5,9 & 43 & 108 & 1,2 & 0,3 & 3,2 & 16 & 620 & 150 & 230 \\
\hline
\end{tabular}


que para MSPA e MSRA, exceção feita à paineira, as doses de P não foram suficientes para atingir a máxima produção (Tabela 2). Tal comportamento sugere que a paineira é uma espécie eficiente nutricionalmente, uma vez que sua produção de biomassa foi mais elevada do que a das demais espécies em todas as doses de P. A observação do índice de eficiência nutricional das espécies, em função da fertilização fosfatada (Fig. 1), sustenta essa sugestão. Respostas distintas entre espécies em relação à fertilização fosfatada também foram observadas em outros estudos (Furtini Neto, 1994; Renó,1994), e podem também ser explicadas por diferenças na eficiência nutricional em relação ao nutriente.

\section{Concentração e frações de $P$ na parte aérea}

$\mathrm{O}$ fornecimento de $\mathrm{P}$ ao solo ocasionou aumento nos teores de Pts, Pi e Po nas folhas de todas as espécies, notadamente nos níveis mais elevados de fertilização fosfatada (300 e $600 \mathrm{mg} \mathrm{dm}^{-3}$ ) (Fig. 2). Em praticamente todas as doses de $\mathrm{P}$, a paineira apre-
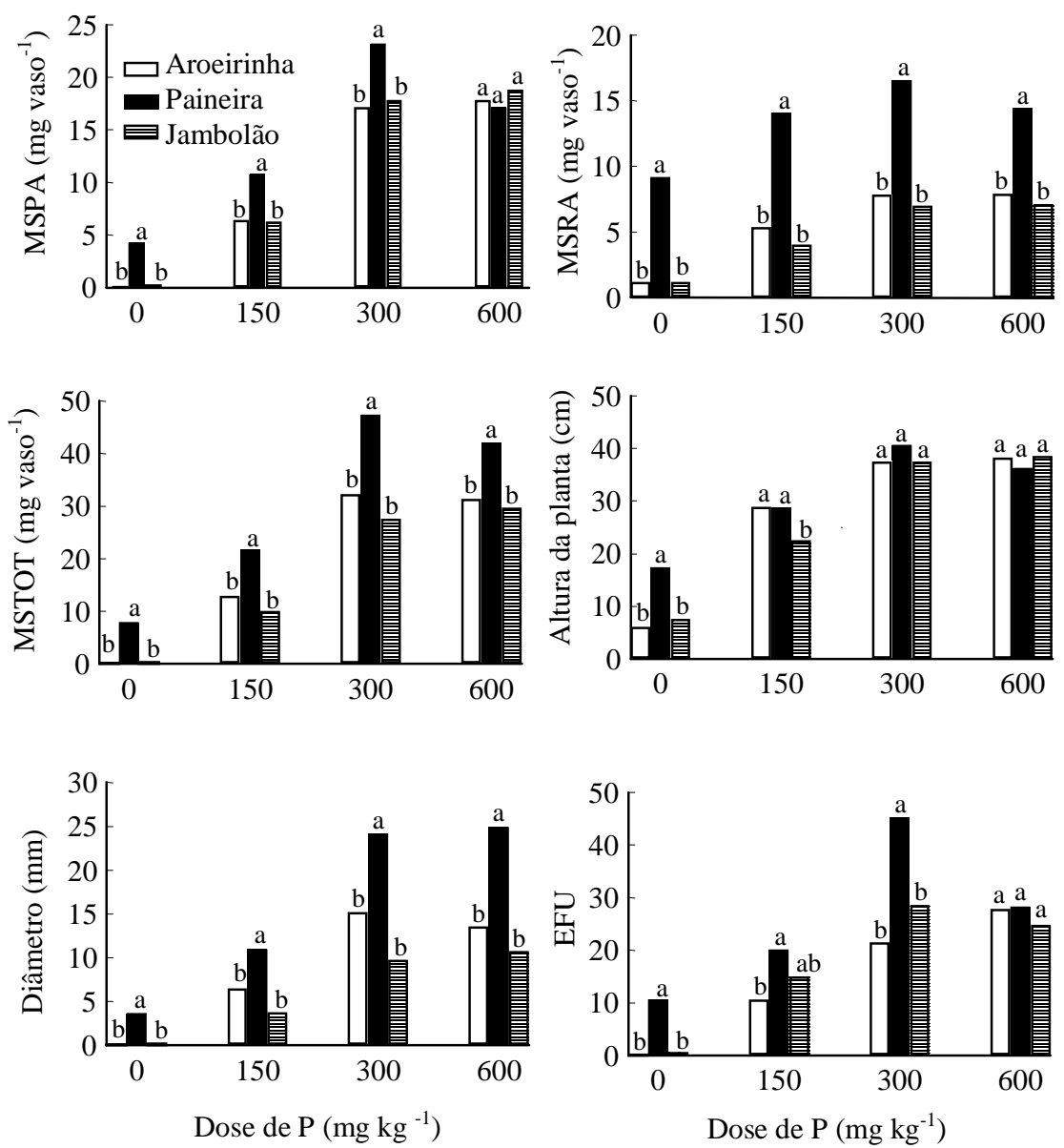

FIG. 1. Matéria seca da parte aérea (MSPA), da raiz (MSRA) e total (MSTOT), altura da planta, diâmetro do caule e eficiência de utilização de $\mathbf{P}(\mathbf{E F U}=\mathbf{M S} / \mathbf{P}$ acumulado $)$ de três espécies florestais em função de doses de fósforo. As barras com letras diferentes indicam diferenças significativas entre as espécies estudadas. 
TABELA 2. Equações de regressão ajustadas para a produção de matéria seca da parte aérea (MSPA), matéria seca de raiz (MSRA) e matéria seca total (MSTOT), das espécies florestais, como variáveis dependentes (Y) das doses de $\mathrm{P}$ aplicadas $(\mathrm{X})$ ao solo, $90 \%$ da produção máxima de matéria seca da parte aérea e dose de $P$ para $90 \%$ da produção máxima de matéria seca da parte aérea.

\begin{tabular}{|c|c|c|c|c|c|}
\hline Espécie & Variável & Equação & $\mathrm{R}^{2}$ & $\begin{array}{l}90 \% \text { da produção } \\
\text { máxima }\left(\mathrm{g} \text { vaso }^{-1}\right)\end{array}$ & $\begin{array}{c}\text { Dose de P para } 90 \% \mathrm{da} \\
\text { produção máxima }\left(\mathrm{mg} \mathrm{dm}^{-3}\right)\end{array}$ \\
\hline \multirow{3}{*}{ Aroeirinha } & MSPA & $Y=1,584+0,03212 X$ & $0,97 * *$ & \multirow{3}{*}{20,86} & \multirow[t]{3}{*}{600} \\
\hline & MSRA & $Y=-0,2323+0,0695 X$ & $0,99 * *$ & & \\
\hline & MSTOT & $Y=-1,4101+0,1477 X-0,0015 X^{2}$ & $0,96 * *$ & & \\
\hline \multirow[t]{3}{*}{ Paineira } & MSPA & $Y=3,5764+0,08904 X-0,00011 X^{2}$ & $0,84 * *$ & \multirow[t]{3}{*}{19,58} & \multirow[t]{3}{*}{267} \\
\hline & MSRA & $Y=5,4634+0,03862 X$ & $0,91 * *$ & & \\
\hline & MSTOT & $Y=5,4272+0,1837 X-0,00020 X^{2}$ & $0,92 * *$ & & \\
\hline \multirow[t]{3}{*}{ Jambolão } & MSPA & $Y=1,590+0,03374 X$ & $0,98 * *$ & \multirow[t]{3}{*}{21,83} & \multirow[t]{3}{*}{600} \\
\hline & MSRA & $\mathrm{Y}=0,9310+0,1899 \mathrm{X}$ & $0,98 * *$ & & \\
\hline & MSTOT & $Y=-1,1875+0,1189 X-0,00023 X^{2}$ & $0,95 * *$ & & \\
\hline
\end{tabular}

** Significativo a $1 \%$ de probabilidade

sentou teores mais elevados de Pts, sugerindo, assim, uma elevada taxa de absorção de P por esta espécie.

Quando se analisam os teores de Pi (Fig. 2), observa-se que todas as espécies mostraram aumento desta fração com o fornecimento do nutriente, notadamente o jambolão, nas doses mais elevadas de P. O Pi vacuolar é considerado como fração de reserva da planta e pode retornar ao citoplasma para atender à exigência metabólica da célula (Bieleski, 1973; Bieleski \& Ferguson, 1983). Se o ritmo de crescimento da planta for lento ou a demanda de $\mathrm{P}$ pequena, um fornecimento elevado do nutriente pode resultar no acúmulo de Pi. Tal observação concorda com os resultados do presente estudo. Em função dos maiores teores de $\mathrm{Pi}$, pode-se inferir também que depois de bem supridas em $\mathrm{P}$, as plantas de jambolão suportariam por mais tempo uma interrupção no fornecimento de $\mathrm{P}$ antes de paralisar seu crescimento, pois neste caso ocorreria a mobilização do Pi vacuolar para o citoplasma celular.

Em todos os níveis de $\mathrm{P}$ aplicados, os teores de Po em folhas da paineira foram mais elevados em comparação às das demais espécies (Fig. 2). Tal comportamento provavelmente é uma das explicações para o maior crescimento dessa espécie sob todas as doses de P (Fig. 1). De acordo com Caradus \& Snaydon (1987), plantas de trevo foram eficientes em reduzir os teores de $\mathrm{Pi}$ a baixas concentrações quando o suprimento de $\mathrm{P}$ era insuficiente. Os maio- res teores de Po nessa condição seriam resultantes da mobilização de íons do vacúolo por meio de alterações na atividade e/ou concentração dos transportadores no tonoplasto, para manter a concentração iônica do citoplasma (Glass \& Siddiqi, 1984). Nesse caso, em função de diferenças genéticas entre as espécies, os graus de ajuste metabólico seriam distintos, resultando em vantagem ou desvantagem adaptativa a determinada condição de nutrição fosfatada. A maior produção de biomassa pelas plantas de paineira em todas as doses de $\mathrm{P}$ poderia ser também explicada por uma melhor eficiência nos ajustes metabólicos dessa espécie.

Pela substituição das doses de $\mathrm{P}$ equivalentes a $90 \%$ da máxima produção de MSPA nas equações de regressão, relacionando os teores de Pts, Pi e Po na parte aérea como variáveis dependentes das doses de $\mathrm{P}$, obtiveram-se os teores críticos destas frações nas espécies avaliadas (Tabela 3 ). Os maiores teores de Pts do jambolão, aroeirinha e paineira, respectivamente 148,131 e $110 \mu \mathrm{g} \mathrm{g}^{-1}$, são coerentes com a concentração de $\mathrm{P}$ total $(\mathrm{Pt})$ determinada por digestão nitroperclórica dessas espécies (Tabela 3). O menor teor de Pt observado na paineira pode ser atribuído ao efeito de diluição (Jarrel \& Beverley, 1981), em razão do maior crescimento das plantas desta espécie.

As doses críticas das diferentes frações fosfatadas, bem como a participação de Pi em relação ao Pts, variaram entre as espécies (Tabela 3). No 

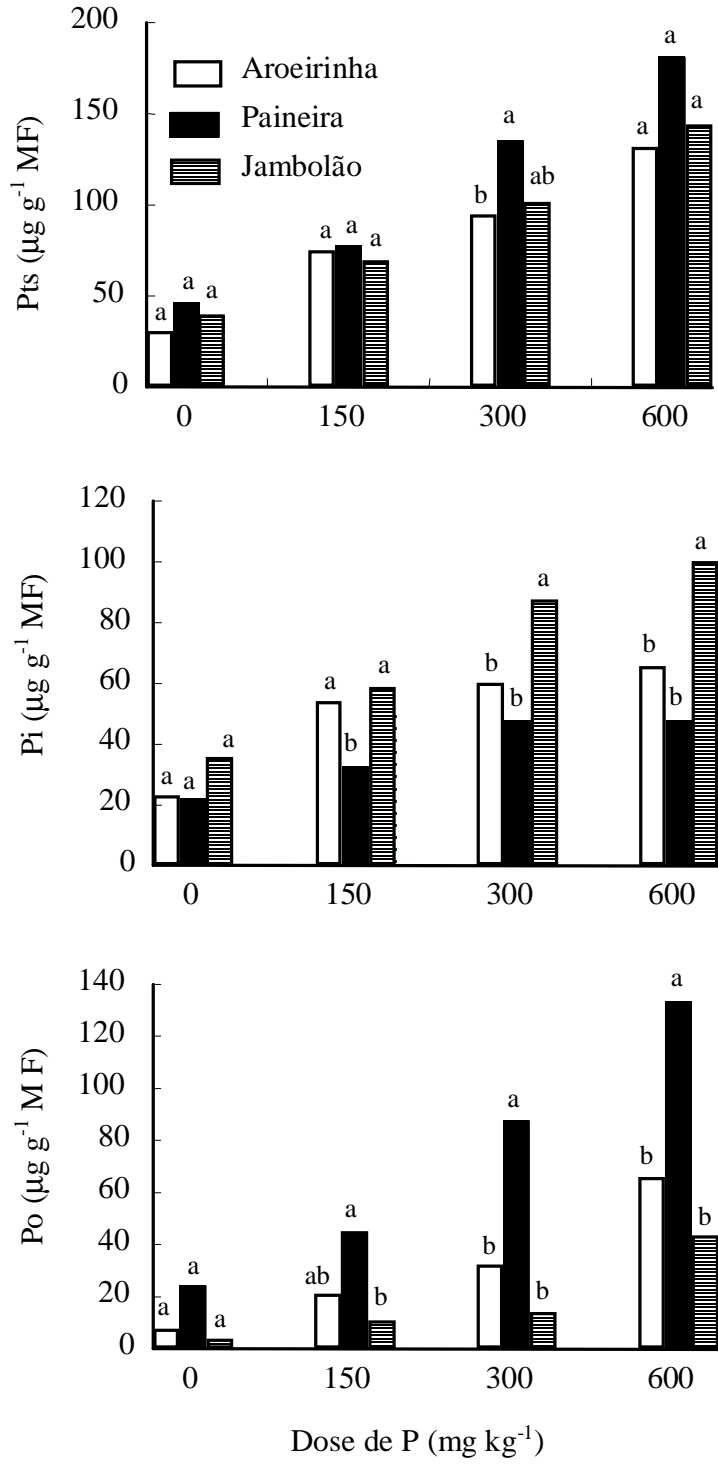

FIG. 2. $P$ total solúvel em ácido (Pts), $P$ inorgânico solúvel em ácido $(\mathrm{Pi})$ e $\mathrm{P}$ orgânico solúvel em ácido (Po) na matéria fresca (MF) de três espécies florestais em função de doses de $P$. As barras com letras diferentes indicam diferenças significativas de resposta entre as espécies estudadas.

caso da aroeirinha, metade do Pts estava presente na forma de Pi, enquanto que no jambolão esta participação foi de $68 \%$, mostrando diferente taxa de ajuste
TABELA 3. Níveis críticos de $P$ inorgânico solúvel em ácido (Pi), $\mathrm{P}$ orgânico solúvel em ácido (Po), P total solúvel em ácido (Pts) e concentração de $P$ total $(\mathrm{Pt})$ na parte aérea de três espécies florestais submetidas a fertilizações fosfatadas.

\begin{tabular}{|c|c|c|c|c|}
\hline \multirow[t]{2}{*}{ Espécie } & \multicolumn{4}{|c|}{ Frações de $\mathrm{P}^{1}$} \\
\hline & $\mathrm{Pi}$ & Po & Pts & $\mathrm{Pt}$ \\
\hline & \multicolumn{3}{|c|}{--------( $\mu \mathrm{g} \mathrm{g}^{-1}$ matéria fresca)-------- } & $(\%)$ \\
\hline Aroeirinha & $65,2(49,7)$ & $64,4(50,3)$ & 131 & 0,09 \\
\hline Paineira & $43,8(39,5)$ & $73,6(60,5)$ & 111 & 0,07 \\
\hline Jambolão & $101,0(68,1)$ & $40,3(31,9)$ & 148 & 0,11 \\
\hline
\end{tabular}

metabólico destas espécies em relação à fertilização fosfatada. Diferenças na dinâmica interna do P entre espécies foram também observadas em outros estudos (Furtini Neto, 1994). É interessante verificar a elevada participação do Po em relação ao Pts na paineira, na dose de $\mathrm{P}$ equivalente a $90 \%$ da máxima MSPA, em comparação com as demais espécies. Sem dúvida, o maior crescimento da paineira pode ser atribuído a esta participação. Apesar de a dose de $\mathrm{P}$ necessária para atingir $90 \%$ da máxima MSPA ser pequena em comparação com as demais espécies (Tabela 2), a paineira se mostrou muito eficiente na conversão de biomassa por unidade do nutriente absorvido, reflexo do seu maior crescimento. A falta de resposta da paineira à adição conjunta de superfosfato e fungo micorrízico no trabalho de Carneiro et al. (1996) pode ser decorrente do maior tamanho (Siqueira et al., 1998), da maior reserva nutricional em sua semente e da maior eficiência de utilização de nutrientes, em particular do P por essa espécie, causada pela mobilização preferencial do $\mathrm{P}$ absorvido na forma de $\mathrm{P}$ orgânico (Po). Em termos práticos, tais observações indicam que a paineira, em comparação com a aroeirinha e o jambolão, é uma espécie que poderia ser alocada em solos com distintos níveis de P, uma vez que seu crescimento foi superior ao das demais, tanto sob alta quanto sob baixa disponibilidade do nutriente.

As observações do presente trabalho indicam um comportamento distinto das espécies florestais em relação à fertilização fosfatada, sugerindo o aprovei- 
tamento dessas diferenças na alocação das espécies em solos com diferentes características em termos de fertilidade.

\section{CONCLUSÕES}

1. A paineira é mais eficiente do que a aroeirinha e o jambolão na absorção de $\mathrm{P}$ sob baixas e altas doses deste elemento.

2. O jambolão, mais exigente do que a aroeirinha, é indicado para solos com maior disponibilidade de $\mathrm{P}$.

\section{REFERÊNCIAS}

BIELESKI, R.L. Phosphate pools, phosphate transport, and phosphate availability. Annual Review of Plant Physiology, Palo Alto, v.24, p.225-252, 1973.

BIELESKI, R.L.; FERGUSON, J.B. Physiology and metabolism of phosphate and its compounds. In LACHLI, A.; BIELESKI, R.L. (Ed.). Encyclopedia of plant physiology: inorganic plant nutrition. Berlin Springer, 1983. p.422-449. (New series, v.15A)

CARADUS, J.R.; SNAYDON, R.W. Aspects of the phosphorus nutrition of white clover populations I. Inorganic phosphorus content of leaf tissue. Journal of Plant Nutrition, New York, v. 10, p.273285,1987

CARNEIRO, M.A.C.; SIQUEIRA, J.O.; DAVIDE, A.C.; GOMES, L.J.; CURI, N.; VALE, F.R. Fungo micorrízico e superfosfato no crescimento de espécies arbóreas tropicais. Scientia Forestalis, Piracicaba, v.50, p.21-36, 1996.

CLARKSON, D.T. Adaptações morfológicas e fisiológicas das plantas a ambientes de baixa fertilidade. In SIMPÓSIO SOBRE RECICLAGEM DE NUTRIENTES E AGRICULTURA DE BAIXOS INSUMOS NOS TRÓPICOS, Ilhéus, 1984. Anais. Ilhéus : CEPLAC/Sociedade Brasileira de Ciência do Solo, 1985. p.45-75.

DAVIDE, A.C.; FARIA, J.M.R.; BOTELHO, S.A. Propagação de espécies florestais. Lavras : UFLA, 1995. 41p.

DIAS, L.E.; ALVAREZ, V.H.; BRIENZA JÚNIOR, S Formação de mudas de Acacia mangium Willd. 2. Resposta a nitrogênio e potássio. Revista Árvore, Viçosa, v.15, n.1, p.11-22, 1991
FABRES,A.S.; NOVAIS, R.F.; NEVES, J.C.L.; BARROS, N.F.; CORDEIRO, A.T. Níveis críticos de diferentes frações de $\mathrm{P}$ em plantas de alface cultivadas em diferentes solos. Revista Brasileira de Ciência do Solo, Campinas, v.11, p.51-57, 1987.

FÖHSE, D.; CLAASSEN, N.; JUNGK, A. Phosphorus efficiency of plants. II. Significance of roots radius, root hairs and cation-anion balance for phosphorus influx in seven plant species. Plant and Soil, Dordrecht, v.132, p.261-272, 1991.

FRANCO, A.A. Fixação de nitrogênio em árvores e fertilidade do solo. Pesquisa Agropecuária Brasileira, Brasília, v.19, s/n, p.253-261, 1984.

FURTINI NETO, A.E. Eficiência nutricional, cinética de absorção e frações fosfatadas em Eucalyptus spp. Viçosa : UFV, 1994. 99p. Tese de Doutorado.

GLASS, A.D.M.; SIDDIQI, M.Y. The control of nutrient uptake rate in relation to the inorganic composition of plants. In: TINKER, P.B.; LAUCHLI, A. (Ed.). Advances in plant nutrition. New York : Praeger, 1984. p.103-147.

HOGUE, E.; WILCOX, G.E.; CANTLIFFE, D.J. Effect of soil phosphorus levels on phosphate fractions in tomato leaves. American Society for Horticultural Science Journal, Alexandria, v.95, n.1, p.174-176, 1970

JARREL, W.N.; BEVERLEY, R.B. The dilution effect in plant nutrition studies. Advances in Agronomy, San Diego, v.34, p.197-224, 1981

LARSON, B.C. Patways of development in mixed-species stands. In: KELTY, M.J.; LARSON, B.C.; OLIVER, C.D. (Ed.). The ecology and silviculture of mixedspecies forest. Dordrecht : Kluwer Academic, 1992, p. $3-10$

MARSCHNER, H.; KIRKBY, E.A.; CAKMAK, I. Effect of mineral nutritional status on shoot-root partioniting of photoassimilates and cycling of mineral nutrients. Journal of Experimental Botany, Oxford, v.47, p. 1255-1263, 1996. Special Issue SI.

MARTINEZ, H.E.P. Cinética da absorção e das frações fosfatadas em sete variedades de soja (Glicine $\max$ L. (Merril)). Viçosa : UFV, 1992. não paginado. Relatório final de Pós-Doutoramento.

RENÓ, N. Requerimentos nutricionais e resposta ao $P$ e fungo micorrízico de espécies nativas no

Pesq. agropec. bras., Brasília, v.35, n.6, p.1191-1198, jun. 2000 
Sudeste brasileiro. Lavras : ESAL, 1994. 62p. Dissertação de Mestrado.

SIDDIQI, M.Y;; GLASS, A.D.M. Utilization index: a modified approach to the estimation and comparison of nutrient utilization efficiency in plants. Journal of Plant Nutrition, New York, v.4, p.289-302, 1981.

SIQUEIRA, J.O.; CARNEIRO, M.A.C.; CURI, N.; ROSADO, S.C.S.; DAVIDE, A.C. Mycorrhizal colonization and mycotrophic growth of native woody species as related to sucessional groups in Southeastern Brazil. Forest Ecology and Management, Amsterdam, v.107, p.241-252, 1998.
SIQUEIRA, J.O.; CURI, N.; VALE, F.R.; FERREIRA, M.M.; MOREIRA, F.M.S. Aspectos de solos, nutrição vegetal e microbiologia na implantação de matas ciliares. Belo Horizonte : CEMIG, 1995. $28 \mathrm{p}$.

SMILLIE, R.M.; KROTKOV, G. The estimation of nucleic acids in some algae and higher plants. Canadian Journal of Botany, Ottawa, v.38, p.31-49, 1960

SUN, J.S.; SIMPSON, R.J.; SANDS, R. Nitrogen activity of two genotypes of Acacia mangium as affected by phosphorus nutrition. Plant and Soil, Dordrecht, v.44, p.51-58, 1992 